\title{
OYĚWÙMí, OYÈrónKẸ́ (2017). LA INVENCIÓN DE LAS MUJERES. UNA PERSPECTIVA AFRICANA SOBRE LOS DISCURSOS OCCIDENTALES DEL GÉNERO. BOGOTÁ: EN LA FRONTERA
}

\author{
Mara Viveros-Vigoya
}

L a publicación en castellano del libro The Invention of Women: Making an African Sense of Western Gender Discourses (1997) de Oyèrónkẹ'Oyěwùmí por la editorial en la frontera es un acto político necesario. Y ningún colectivo podría haber impulsado mejor esta tarea que el Grupo Latinoamericano de Estudio, Formación y Acción Feminista (GLEFAS), espacio colectivo regional desde el cual se plantean reflexiones situadas y se articulan, como en pocos ámbitos, teoría y práctica feminista, academia y movimiento social. Este libro llega, además, en un momento muy oportuno, como una adición necesaria al corpus de trabajo de las feministas del sur global, para hacer conocer al público hispanoparlante lo que hace ya veinte años planteó la socióloga nigeriana, de origen yorubá, Oyèrónkẹ' Oyěwùmí: la importancia de producir conceptos desligados de los paradigmas teóricos europeos y anclados en las realidades locales.

Este libro comenzó siendo una tesis de doctorado en sociología de la Universidad de Berkeley como un estudio de género en la sociedad yorubá contemporánea, pero poco a poco la autora se fue deslindado de los marcos teóricos disciplinarios, tanto de la sociología como de los estudios feministas y de género, al descubrir que la categoría "mujer", piedra angular de los discursos occidentales de género, no era una categoría propia del contexto yorubá, sino que en esta sociedad se utilizaba por el contacto con el mundo occidental.

El riguroso análisis interno de la sociedad oyóyorubá, situada en el oeste de Nigeria, que hace Oyěwùmí, le permite identificar el núcleo de lo que afecta desde hace mucho tiempo y hasta hoy el estudio de las sociedades africanas, las perspectivas de conocimiento hegemónicas y las definiciones externas. La tesis central del trabajo de Oyèrónkẹ' Oyěwùmí, publicado originalmente en 1997, consiste, en primer lugar, en negar que el género funcione como un principio básico de organización en todas las sociedades, y, en segundo lugar, en mostrar la inconveniencia de los postulados teóricos del feminismo euroamericano para dar cuenta de la cultura oyó-yorubá y, más ampliamente, de las culturas africanas. Ella plantea que, en la medida en que los discursos feministas académicos occidentales han producido un relato de las mujeres como "las nopoderosas" $\mathrm{y}$ "las desprovistas de los atributos del falo", este recuento es inadecuado para analizar las mujeres anatómicas de la sociedad yorubá precolonial.

Oyěwùmí sugiere que, mientras en las sociedades europeas el cuerpo físico está siempre ligado al cuerpo social, en el pensamiento yorubá esta biologización de la diferencia no existe. Tampoco es una sociedad que privilegia lo visual, la apariencia o los marcadores visibles

Mara Viveros Vigoya. Universidad Nacional de Colombia. Correo electrónico: mviverosv@unal.edu.co. 
de la diferencia, en contraste con una epistemología occidental que basa sus categorías y jerarquías en modos visuales y en distinciones binarias: hombres y mujeres, blancos y negros, homosexuales y heterosexuales, etcétera. Su principal afirmación es que, a diferencia de las europeas, las culturas africanas no son, y todavía no han sido, clasificadas según una lógica de visión, sino por otros sentidos, por lo que la noción de "cosmovisión" sólo es apropiada para las sociedades eurocentradas; ella propone que el "sentido del mundo", una noción muy sugerente, corresponde mejor a la forma yorubá de conocimiento.

Oyěwùmí cuestiona, fundamentalmente, la idea de que el esquema categórico occidental para entender las dinámicas sociales pueda ser exportado sin reparos, y por esto tampoco quiere hacer generalizaciones gratuitas sobre las sociedades africanas para no repetir el gesto de colonización discursiva que llevan a cabo buena parte de quienes estudian el continente africano, de modo que homogeneízan de forma injustificada su diversidad social y cultural. El argumento de la autora es que, antes de la colonización de Occidente, el principio básico organizativo de la sociedad yorubá era el sistema de "senioridad" (seniority), definido en forma relacional, y que el género no era una forma relevante de ordenamiento de sus prácticas sociales.

Esta afirmación le implicó, como ella señala, recartografiar su orden social y buscar en el lenguaje, como institución que afecta y expresa los modos de interacción social, algunas claves explicativas. Así, si la lengua inglesa, y aún más las lenguas romances como el castellano, hacen tantas diferenciaciones de género, es porque éstas son las distinciones relevantes para estas sociedades. En contraste, y de acuerdo con el estudio de Oyěwùmí, la lengua yorubá indica la ausencia de atribuciones sexuales. Por ejemplo, en la familia yorubá, omo, la palabra para designar al infante, se traduce mejor como progenie y designa por igual a niñas y niños. En cuanto a la categoría oko, que generalmente se entiende como la traducción de palabra inglesa husband, vale la pena mencionar que ésta es concretamente neutral al género y abarca tanto a hombres, como a mujeres.
El estudio de Oyěwùmí plantea igualmente que, si en la lengua yorubá no hay especificidades de género, pero sí indicativos de senioridad, y si las instituciones sociales y prácticas yorubá no hacen distinciones sociales ni determinan posiciones o estatus fundados en diferencias anatómicas, es porque en la tierra yorubá las diferencias sexuales no fueron la base de las categorías sociales. El sustento de su afirmación de la importancia de la senioridad como principio básico de esta organización social es el lugar que atribuye al lenguaje como principal fuente de información del sentido del mundo, de los cambios históricos y de los modos de interpretación de la estructura social. Lo que se codifica lingüísticamente en yorubá es la "senioridad", y éste es el elemento que ordena y divide a la sociedad yorubá.

En lugar de la lógica visual de informar sobre la división social y la jerarquía a través de estructuras como el género, la sexualidad, la raza y la clase, la sociedad yorubá ubica la senioridad en el centro de su organización lingüística y social. Esta categoría se refiere a la diferencia en la edad cronológica, pero sobre todo al posicionamiento de cada agente en la estructura de parentesco. En estos arreglos familiares los lazos de sangre son superiores a los lazos de alianza. Y entre quienes comparten lazos de sangre, la senioridad se basa en el orden de los nacimientos, de modo que el primogénito es superior a todos los demás retoños. Sin embargo, para el pariente por alianza, su rango de senioridad depende del número de hijos que ya forman parte del linaje; por lo tanto, la senioridad es siempre relativa y depende del contexto, de manera que nadie ocupa definitivamente una posición superior o menor, sino que depende de quién está presente en una situación dada.

Así, incluso si " $\mathrm{x}$ " es el primogénito - y por lo tanto superior a otros miembros del linaje-, y si "x" se casa, entonces es automáticamente "menor" en relación con el linaje del cónyuge. En resumen, la senioridad funciona como una cadena de mando en esta sociedad, pero siempre en términos de un sistema patrilineal, hecho que, entre otras cosas, no es ni muy teorizado ni problematizado por Oyěwùmí, quien está 
primordialmente interesada en demostrar la disociación entre riqueza, rango y sexo y la centralidad social de la senioridad.

Hay mucho que admirar en el desafío de Oyěwùmí a los supuestos sobre la universalidad de las categorías de género como principio fundamental de organización en todas las sociedades y momentos de la historia. La autora pone en evidencia que, asumir a priori el género como una categoría pertinente de diferenciación social, o la existencia de las "mujeres" como grupo social en nuestras sociedades, tiene muchos implícitos que vale la pena interrogar: iexpresan las realidades de los contextos que buscamos comprender y analizar?, ¿o más bien incorporan categorías elaboradas en contextos históricos y culturales específicos que pretenden ser universales y de las cuales nos apropiamos sin detenernos a analizar su pertinencia?

El punto que vale la pena resaltar del trabajo de Oyěwùmí es su cuestionamiento de esta adopción acrítica de categorías "externas" para analizar las dinámicas locales de estructuración social. Y esto es válido en ambas direcciones, porque si los términos occidentales de género no se traducen directamente en yorubá, el sistema de senioridad yorubá tampoco se traduce ni tiene necesariamente pertinencia en otros contextos culturales por más próximos que parezcan. En cualquier caso, la cuestión crucial de cualquier investigación sigue siendo la atención que se preste a las especificidades de la experiencia cultural local y de la estructura social, para dejarnos guiar por ellas y no por los mandatos teóricos de nuestro pequeño mundo académico. En el enfoque de Oyěwùmí también es muy importante otro argumento: la forma en que entramos en un campo de investigación y las preguntas que planteamos determinarán parcialmente el resultado logrado. Así, si formulamos preguntas de género en sociedades en las cuales los principios organizativos básicos son otros, o si enmarcamos teóricamente nuestras observaciones en una "perspectiva de género", corremos el riesgo de producir siempre respuestas de género. De nuevo, vale la pena recordar, una y otra vez, que los conceptos y las categorías nunca son "objetivos" y, por el contrario, siempre están atrapados en la dinámica de las relaciones de poder y en el campo de la cultura misma que los produce.

Como cualquier trabajo, la investigación de Oyěwùmí puede ser objeto de críticas. La más conocida es la realizada por otra académica e investigadora nigeriana Bibi Bakare-Yusuf. Si bien ella reconoce la fuerza convincente de su texto, señala dos aspectos problemáticos en los argumentos de Oyěwùmí. En primer lugar, su asunción de que las palabras del lenguaje yorubá siempre han tenido el mismo significado, como si el lenguaje no fuera desde siempre dinámico; es decir, sin historizar el principio de senioridad. Sin embargo, diré a favor de Oyěwùmí que ella es consciente del constante cambio que viven los lenguajes africanos, incluido el yorubá, como efecto de la imposición de las lenguas y estructuras sociales europeas en las sociedades africanas. De hecho, una de las principales transformaciones en la cultura yorubá que ella documenta es la progresiva importancia que adquieren las categorías de género en el lenguaje, la literatura y la sociedad. Por otra parte, para las y los académicos occidentales, moldeados por sus estructuras lingüísticas, es muy difícil, por ejemplo, acercarse a la realidad social de las hembras oko, que ofician de lo que podría llamarse "maridos" de otra mujer, sin pensar con categorías sexuales como "homosexualidad" y "travestismo"; es decir, sin traducir posiciones sociales en posiciones sexuales.

Una segunda crítica al trabajo de Oyěwùmí es su entendimiento de las dinámicas del poder. Parecería que ignora que la senioridad no es la única forma en que actúan las relaciones de poder, cuyos modos de operar son además interdependientes de otros; su conclusión de que las mujeres y los hombres yorubá tienen el mismo poder e iguales oportunidades porque en su lenguaje las distinciones de género no son jerárquicas, sino anatómicas, puede terminar confundiendo lenguaje y realidad social, y dejar de lado observaciones que pueden dar cuenta de la forma en que la senioridad enmascara o podría ser el significante de otras relaciones de poder que podrían ser descritas en términos de género.

Pese a esta debilidad, que me parece más pertinente que la primera, Oyěwùmí logra demostrar con amplitud, 
en primer lugar, la necesidad de encontrar formas explicativas surgidas de los contextos africanos específicos sin acudir a conceptos europeos como, por ejemplo, el sistema de familia nuclear, para interpretar la experiencia africana sin distorsionarla; $y$, en segundo lugar, la existencia de otras formas de opresión y reconocimiento tanto o más importantes que el género en las sociedades no occidentales.

En los contextos occidentalizados, autoras afroamericanas como Hazel Carby (Reconstructing Womanhood: The Emergence of the Afro-American Woman Novelist, 1987) y Hortense Spillers ("Mama's Baby, Papa's Maybe: An American Grammar Book", 1987) también cuestionaron, a partir de las experiencias de las mujeres racializadas como negras en Norteamérica, teorías eurocentradas como la de Gayle Rubin ("The Traffic in Women: Notes on the 'Political Economy' of Sex", 1975), que vincula la opresión de las mujeres a la institución del parentesco y a los discursos de feminidad. Carby sostuvo hace treinta años que las mujeres negras no habían sido constituidas como "mujeres" de la misma manera que lo habían sido las mujeres blancas, esto porque la institución de la esclavitud las había excluido de la "cultura", definida como la circulación de signos a través del sistema de intercambio matrimonial.
Para Carby, las mujeres negras fueron sexualmente marcadas como hembras - animales-, pero no como mujeres - esposas potenciales que podían transmitir un apellido-. En ese sentido, si bien las mujeres blancas eran intercambiadas en un sistema de sexo/género que las oprimía, la institución de la esclavitud había producido a grupos enteros de personas - mujeres y hombres negros - como propiedad enajenable de los hombres, y las mujeres, blancos.

La especificidad de la experiencia del sexismo de las mujeres afroestadounidenses explica, para Spillers ("Mama's Baby, Papa's Maybe: An American Grammar Book", 1987), su necesidad de construir discursos alternativos de la feminidad y reclamar la autoridad para representarse a sí mismas y autoconstituirse como sujetos. Éste fue el llamado que profundizó Oyèrónkẹ Oyěwùmí. En su propuesta, no sólo se trata de exigir la autoridad para que las sociedades africanas puedan representarse a sí mismas y la legitimidad de elaborar un pensamiento propio; se trata de cuestionar la universalidad de categorías como mujeres (hombres) y feminidad (masculinidad), sobre las cuales se ha construido el andamiaje del binarismo del todavía hegemónico pensamiento occidental. iUn gesto desafiante de inigualable valentía! 